\title{
Histopathologic evaluation of liver metastases from colorectal cancer in patients treated with FOLFOXIRI plus bevacizumab
}

\author{
F Loupakis ${ }^{* 1,2,5}$, M Schirripa ${ }^{1,2,5}$, C Caparello ${ }^{1,2}$, N Funel $^{3}$, L Pollina ${ }^{4}$, E Vasile $^{1,2}$, C Cremolini $^{1,2}$, \\ L Salvatore ${ }^{1,2}$, M Morvillo ${ }^{1}$, C Antoniotti ${ }^{1,2}$, F Marmorino $^{1,2}$, G Masi $^{1,2}$ and A Falcone ${ }^{1,2}$ \\ ${ }^{1}$ Unit of Medical Oncology 2, Azienda Ospedaliero-Universitaria Pisana, via Roma 57, 56126 Pisa, Italy; ${ }^{2}$ Division of Medical \\ Oncology, Department of Translational Research and New Technology in Medicine and Surgery, University of Pisa, \\ via Roma 57, 56126 Pisa, Italy; ${ }^{3}$ Unit of Pathology 3, Department of Surgical Pathology, University of Pisa, via Roma 57, \\ 56126 Pisa, Italy and ${ }^{4}$ Unit of Pathology 2, Department of Laboratory Medicine and Molecular Diagnosis, Azienda \\ Ospedaliero-Universitaria Pisana, via Roma 57, 56126 Pisa, Italy
}

Background: The FOLFOXIRI regimen produces a high rate of radiological and histopathological responses. Bevacizumab added to chemotherapy showed an improvement in pathological response and necrosis of colorectal liver metastases (CLMs). FOLFOXIRI plus bevacizumab produced promising early clinical results and is under investigation in several randomised trials, although no data are currently available on its effects on response of CLMs and on liver toxicities.

Methods: Starting from 499 patients enrolled in first-line phase II/III trials, we selected on the basis of tissue sample availability 18 patients treated with FOLFOXIRI/XELOXIRI and 24 patients treated with FOLFOXIRI plus bevacizumab who underwent secondary resection of CLMs. The 28 untreated patients who underwent primary resection of CLMs were included as control group. Responses of CLMs and chemotherapy-induced toxicities were assessed.

Results: Among the patients, $63 \%$ of those treated with FOLFOXIRI plus bevacizumab, as compared with $28 \%$ of those treated with only FOLFOXIRI/XELOXIRI, showed a histopathological response $(P=0.033)$. In the two groups, $52 \%$ and $12.5 \%$, respectively, showed necrosis $\geqslant 50 \%(P=0.017)$. The incidence of liver toxicities was not significantly increased in patients treated with FOLFOXIRI plus bevacizumab.

Conclusion: The addition of bevacizumab to FOLFOXIRI produces high rates of pathologic responses and necrosis of CLM without increasing liver toxicity.

\begin{abstract}
Despite major advances in medical treatment of metastatic colorectal cancer (mCRC), radical surgical resection is the only treatment that gives a chance of cure. In most cases, metastatic lesions are unresectable at diagnosis (Wood et al, 1976; Wagner et al, 1984), but given the strong correlation between response rate and secondary resection rate of metastases (Folprecht et al, 2005), first-line chemotherapy with a combination of the most active drugs can be used in selected patients with initially unresectable disease in order to make surgery possible (Adam et al, 2004; Alberts et al, 2005; Poston
\end{abstract}

et al, 2006). The addition of irinotecan or oxaliplatin to 5-fluorouracil improved the activity of the fluoropyrimidine alone (Douillard et al, 2000; de Gramont et al, 2000; Saltz et al, 2000). The intensive threedrug combination FOLFOXIRI compared with the FOLFIRI regimen in a first-line phase III clinical trial conducted by the Gruppo Oncologico Nord-Ovest (GONO) demonstrated an improvement in response rate (RR), $60 \%$ vs $34 \%$, and in R0 secondary resections, $15 \%$ vs $6 \%$, as well as a benefit in terms of progression-free survival (PFS) and overall survival (OS) (Falcone et al, 2007).

\footnotetext{
${ }^{*}$ Correspondence: Dr F Loupakis; E-mail: fotiosloupakis@gmail.com

${ }^{5}$ These authors contributed equally to this work.
} 
In the past few years, the addition of a monoclonal antibody (such as the anti-EGFRs, cetuximab and panitumumab or the antiVEGF bevacizumab) to fluoropyrimidine-based doublets has become the standard of care for the vast majority of mCRC patients. The addition of bevacizumab to a first-line chemotherapy doublet demonstrated a marked improvement in PFS (Hurwitz et al, 2004; Saltz et al, 2008) but the effect in terms of RR seems to be weak $(\mathrm{OR}=1.16,95 \% \mathrm{CI}=0.97-1.38)$ (Loupakis et al, 2010), leading to hypothesise that the antiangiogenic antibody might have a cytostatic more than a cytotoxic effect and consequently a marginal role as shrinking agent. Nevertheless, in a phase II study, the association of bevacizumab with an intensive treatment such as the FOLFOXIRI regimen was demonstrated to be safe and well tolerated, producing a RR of $77 \%$ and a disease control rate of $100 \%$, with $32 \%$ of patients achieving a surgical resection of metastases and a 26\% rate of $\mathrm{R} 0$ resection (Masi et al, 2010).

The role of bevacizumab and its pros and cons in the preoperative treatment (neoadjuvant or conversion) of CRC metastatic to the liver are still controversial issues. Recent studies correlated the histopathological response to chemotherapy with clinical outcome of patients undergoing secondary resection of liver metastases (Rubbia-Brandt et al, 2007; Blazer et al, 2008), and bevacizumab seems to improve the pathologic response of colorectal liver metastases (CLMs), both in terms of viable tumour cells (Ribero et al, 2007; Kishi et al, 2010) and of histopathological regression grade (Klinger et al, 2010). Bevacizumab also seems to increase the degree of necrosis in the CLMs of patients undergoing secondary resection (Wicherts et al, 2011); however, the correlation between tumour necrosis and clinical outcome is still unclear.

The histopathological examination in terms of chemotherapyinduced liver toxicities represents a controversial issue in patients treated with an intensive chemotherapy regimen in association with a biologic agent. Every single cytotoxic agent is related to a specific liver toxicity (Rubbia-Brandt et al, 2004; Fernandez et al, 2005; Aloia et al, 2006; Vauthey et al, 2006) and the use of bevacizumab has raised the issue of perioperative complications because of its mechanism of action, mainly the risk of bleeding, wound healing and liver regeneration (Gruenberger et al, 2008).

In the present study we analysed hepatic tissue samples from resected patients receiving FOLFOXIRI with or without bevacizumab to investigate the role of anti-VEGF in association with an intensive first-line regimen on response of CLMs, in terms of complete pathological response, tumour regression grade, tumour necrosis and fibrosis and on treatment-related hepatic toxicities. We also included in our analyses a chemotherapy-naive cohort of patients as control group.

\section{MATERIALS AND METHODS}

Selection criteria and treatments. We retrospectively reviewed archival liver specimens from 499 patients enrolled in multicentric first-line phase II or III clinical studies (Masi et al, 2004; Falcone et al, 2007; Vasile et al, 2009; Masi et al, 2010) investigating FOLFOXIRI $(N=154)$, XELOXIRI $(N=36)$ or FOLFOXIRI plus bevacizumab $(N=309)$.

On the basis of tissue availability, 42 patients with CRC who underwent secondary resection of liver metastases were included in this analysis.

Patients $(N=24)$ who received a first-line treatment with FOLFOXIRI plus bevacizumab were matched together in the 'bevacizumab group'.

Patients $(N=18)$ who received a first-line treatment with FOLFOXIRI $(N=13)$ or XELOXIRI $(N=5)$ were gathered up in a second group, named as 'chemotherapy group'.
Treatment dosage and schedules were the following: FOLFOXIRI (irinotecan $165 \mathrm{mg} \mathrm{sqm}^{-1}$, oxaliplatin $85 \mathrm{mgsqm}^{-1}$ and folinic acid $200 \mathrm{mg} \mathrm{sqm}^{-1}$ on day 1 and fluorouracil $3200 \mathrm{mg} \mathrm{sqm}^{-1}$ for $48 \mathrm{~h}$ continuous infusion starting on day 1, administered every 2 weeks), FOLFOXIRI plus bevacizumab (as reported above plus bevacizumab $5 \mathrm{mg} \mathrm{kg}^{-1}$ on day 1 before chemotherapy) and XELOXIRI (irinotecan $165 \mathrm{mg} \mathrm{sqm}^{-1}$ and oxaliplatin $85 \mathrm{mg} \mathrm{sqm}^{-1}$ on day 1 , capecitabine $2000 \mathrm{mg} \mathrm{sqm}^{-1}$ b.i.d. from day 1 to day 7 , every 2 weeks).

All the patients included in the above-mentioned trials were required to have unresectable and measurable metastatic disease, an ECOG PS $\leqslant 2$ if $<70$ years of age or an ECOG PS $=0$ if aged between 70 and 75 years and adequate hepatic, renal and bone marrow function. Disease was re-assessed every 8 weeks using CT scan. A multidisciplinary team comprising medical oncologists, interventional radiologists and liver surgeons re-evaluated all potentially resectable patients every 8 weeks in order to define the best resection strategy.

For each patient the following basal characteristics were collected: age at the time of diagnosis of metastatic disease, ECOG PS, sex, primary tumour site (colon vs rectum), liver only metastases (yes vs no), time to metastases (synchronous vs metachronous), previous adjuvant chemotherapy (yes $v s$ no) and number of conversion therapy cycles (i.e., the number of cycles administered preoperatively). All patients were evaluated for response and progression according to RECIST criteria version 1.0.

A total of 28 consecutive chemotherapy-naive patients who underwent primary liver resection and came to our centre for consultancies and follow-up visits over a 1-year period (May 2010 to May 2011) were included in the analysis as the 'control group'.

Histopathological examination. A pathologist with hepatobiliary expertise who was blinded to received treatment and outcome of patients evaluated the resected specimens. Pathologic complete response ( $p C R$ ) was defined as the complete absence of tumour cells replaced by fibrosis and/or necrosis. Tumour regression grade (TRG) was analysed as previously defined by Rubbia-Brandt et al (2007). Briefly, TRG1 corresponded to absence of tumour cells replaced by abundant fibrosis; TRG2 to rare scattered residual tumour cells and abundant fibrosis; TRG3 to a large amount of residual tumour cells with predominant fibrosis; TRG4 to tumour cells predominating over fibrosis; and TRG5 to almost exclusively tumour cells without fibrosis. The mean percentages of necrosis and fibrosis were assessed as previously reported (Aloia et al, 2006; Rubbia-Brandt et al, 2007; Wicherts et al, 2011). For patients with multiple CLMs who showed different TRGs, necrosis and fibrosis percentage were categorised according to the morphological aspect of the worse metastasis.

Nontumoural liver tissue surrounding the metastases was reviewed to define the drug-related hepatic toxicity. The presence of sinusoidal dilation was graded according to Rubbia-Brandt scoring system (0 indicated the absence of sinusoidal dilation, 1 mild with centrilobular involvement limited to approximately one-third of the lobular surface, 2 moderate with centrilobular involvement extending in approximately two/thirds of the lobular surface, and 3 severe with complete lobular involvement) (RubbiaBrandt et al, 2004). Steatosis and steatohepatitis were analysed and graded according to the nonalcoholic steatohepatitis (NASH) clinical research network scoring system (Kleiner et al, 2005). Parenchymal necrosis was described as present or absent (RubbiaBrandt et al, 2004).

Statistical analysis. The aims of our analyses were to estimate the effects in terms of histopathological response and liver toxicity of (1) the addition of bevacizumab to the FOLFOXIRI/XELOXIRI regimens ('bevacizumab group' vs 'chemotherapy group') and (2) the adoption of such intensive treatments (all treated patients $v s$ 'control group' of chemo-naive patients). Discrete variables 
expressed as number and percentage were compared using Fisher's exact test or the $\chi^{2}$ test, when appropriate. Comparisons between means were assessed with the $t$-test. Statistical significance was defined as two-sided $P<0.05$. One-sided $P<0.05$ was adopted when treated patients were compared with the 'control group'. Exploratory correlation analyses of pathologic response and necrosis with outcome in terms of survival were performed by means of Kaplan-Meier curves and log-rank test.

All statistical calculations were performed using the GraphPad Prism software package, version 5.0 (GraphPad Software Inc., San Diego, CA, USA) and R software, version 2.10.0 (R Foundation for Statistical Computing, Vienna, Austria).

\section{RESULTS}

The main patient characteristics were well balanced in the two groups and are described in Table 1. We compared (1) 'bevacizumab group' with 'chemotherapy group' in order to estimate the effect of bevacizumab (Table 2) and (2) treated patients with 'control group' to estimate the overall effect of an intensive treatment (Table 3), according to each variable tested.

The median number of cycles of conversion therapy in the 'bevacizumab group' and in the 'chemotherapy group' was 8 (range 4-12) and 12 (range 8-12), respectively. In the 'bevacizumab group', $15 \%$ of cycles were delayed and $20 \%$ of cycles were administered with a dose reduction. Bevacizumab was prematurely stopped because of refractory uncontrolled hypertension in 1 patient. In the 'chemotherapy group', $17 \%$ of cycles were delayed and 19\% of cycles were administered with a dose reduction. Relative dose intensity of 5-FU, oxaliplatin and irinotecan did not differ between the two groups.

Pathologic complete response was detected in $16 \%$ of patients in the 'bevacizumab group' and in $11 \%$ of patients in the 'chemotherapy group' $(P=0.685)$. Patients showing a histopathological response (TRG 1,2 or 3 ) were $63 \%$ in the bevacizumab group' and $28 \%$ in the 'chemotherapy group' $(P=0.033)$. In particular, $16 \%, 17 \%$ and $30 \%$ achieved respectively a TRG 1,2 or 3 in the 'bevacizumab group'. The same percentage was $11 \%, 6 \%$ and $11 \%$ in the 'chemotherapy group' $(P=\mathrm{NS})$. Patients showing no response (TRG 4 or 5 ) were $37 \%$ and $72 \%$ in the two groups, respectively. The odds ratio for achieving a pathologic response (TRG 1,2 or 3 ) in the 'bevacizumab group' was 1.833 (95\% $\mathrm{CI}=1.045-3.217)$ in comparison with the 'chemotherapy group'. In the 'control group' only one patient (3.5\%) showed a TRG $<4$ (TRG 3), and all other patients showed TRG 4 or 5.

Mean percentage of tumoural fibrosis was $22 \%$ in the 'bevacizumab group', 30\% in the 'chemotherapy group' and 6\% in the 'control group' ('bevacizumab-group'vs chemotherapygroup $P=0.25$; treated $v s$ controls $P<0.0001$; Figure 1). Patients with a fibrosis rate $\geqslant 40 \%$ were $30 \%, 37.5 \%$ and $3.5 \%$ in the three groups respectively ('bevacizumab group' $v s$ 'chemotherapy group' $P=0.74$; treated $v s$ controls $P=0.002$ ).

Mean percentage of tumoural necrosis was $42 \%$ in the 'bevacizumab group', 20\% in the 'chemotherapy group' and 19\% in the 'control group' ('bevacizumab group' vs 'chemotherapy group' $P=0.003$; treated $v s$ controls $P=0.012$ ). Adopting an exploratory cutoff of $50 \%$, patients with a necrosis rate $\geqslant 50 \%$ were $52 \%, 12.5 \%$ and $3.5 \%$ in the three groups respectively ('bevacizumab-group' vs 'chemotherapy-group' $P=0.017$; treated $v s$ controls $P<0.001$; Figure 2). In the 'bevacizumab group' the odds ratio for necrosis $\geqslant 50$ was $1.948(95 \% \mathrm{CI}=1.192-3.184)$ in comparison with patients treated with chemotherapy only.

Chemotherapy-induced liver toxicity. Sinusoidal dilation of any grade was detected in $78 \%$ samples in the 'bevacizumab group' (43\% grade 1 and $35 \%$ grade 2), in $67 \%$ samples in the 'chemotherapy group' (39\% grade 1 and $28 \%$ grade $2 ; P=0.488$ )
Table 1. Clinical characteristics of patients

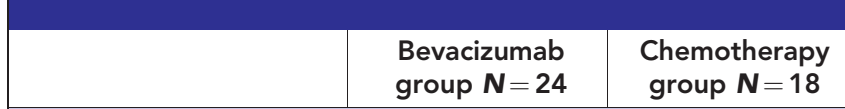

Sex

\begin{tabular}{|l|c|c|}
\hline M & $16(67 \%)$ & $15(83 \%)$ \\
F & $8(33 \%)$ & $3(17 \%)$ \\
\hline
\end{tabular}

Age

\begin{tabular}{|c|c|r}
\hline Median & 60 & 64 \\
\hline & $33-74$ & $45-67$ \\
\hline
\end{tabular}

\begin{tabular}{l|r|r} 
Range & $33-74$ & $45-67$
\end{tabular}

ECOG PS

\begin{tabular}{|l|c|c|}
\hline 0 & $19(79 \%)$ & $16(89 \%)$ \\
1 & $5(21 \%)$ & $2(11 \%)$ \\
\hline
\end{tabular}

Primary tumour

\begin{tabular}{|l|c|c|}
\hline Colon & $18(75 \%)$ & $17(94 \%)$ \\
Rectum & $6(25 \%)$ & $1(6 \%)$ \\
\hline
\end{tabular}

Previous adjuvant CT

\begin{tabular}{|l|c|c|}
\hline Yes & $2(8 \%)$ & $4(22 \%)$ \\
No & $22(92 \%)$ & $14(73 \%)$ \\
\hline
\end{tabular}

Time to metastases

\begin{tabular}{|l|c|c|}
\hline Metachronous & $3(12 \%)$ & $6(33 \%)$ \\
Synchronous & $21(88 \%)$ & $12(67 \%)$ \\
\hline
\end{tabular}

\begin{tabular}{|c|c|c|}
\hline \multicolumn{3}{|c|}{ Liver-only metastases } \\
\hline Yes & 19 (79\%) & $18(100 \%)$ \\
\hline No & $5(21 \%)$ & $0(0 \%)$ \\
\hline
\end{tabular}

Cycles of conversion therapy

\begin{tabular}{|l|l|l}
\hline Median (range) & $8(4-12)$ & $12(8-12)$ \\
\hline
\end{tabular}

No. of resected lesions

\begin{tabular}{|l|l|l}
\hline Median (range) & $3(1-10)$ & $3(1-9)$
\end{tabular}

Diameter per lesion at resection

\begin{tabular}{|l|l|l|}
\hline Medium & $3.5 \mathrm{~cm}$ & $3.0 \mathrm{~cm}$ \\
\hline
\end{tabular}

Postresection treatment

\begin{tabular}{|l|c|c|}
\hline Yes & $17(71 \%)$ & $2(11 \%)$ \\
No & $7(29 \%)$ & $16(89 \%)$ \\
\hline
\end{tabular}

Abbreviations: $\mathrm{CT}=$ chemotherapy; ECOG PS = Eastern Cooperative Oncology Group Performance Status; $F=$ female; $M=$ male.

and in $48 \%$ samples in the 'control group' (only grade 1; treated $v s$ controls $P=0.045)$. None of the samples showed grade 3 sinusoidal dilation. Parenchymal steatosis was $>5 \%$ in $30 \%$ specimens in the 'bevacizumab group', $39 \%$ in the 'chemotherapy group' $(P=0.74)$ and $17 \%$ in the 'control group' (treated vs controls $P=0.107)$. Steatohepatitis was evident in $13 \%$ specimens in the 'bevacizumab-group', $6 \%$ in the 'chemotherapy group' $(P=0.62)$ and $4 \%$ in the 'control group' (treated $v s$ control patients $P=0.404)$. In the 'bevacizumab group', $9 \%$ of the samples showed parenchymal necrosis compared with $33 \%$ in the 'chemotherapy group' $(P=0.1)$. None of the control patients showed parenchymal necrosis (treated $v s$ controls $P=0.025$ ).

Exploratory outcome analyses. In the population of treated patients $(N=42)$, subjects with a pathologic response (TRG 1,2 or 3 ) showed an advantage in terms of PFS in comparison with 
Table 2. Comparison of response and toxicity parameters in bevacizumab group and chemotherapy group

\begin{tabular}{l|r} 
Bevacizumab & $\begin{array}{r}\text { Chemotherapy } \\
\text { group } N=18\end{array}$
\end{tabular}

\section{Pathologic complete response}

\begin{tabular}{|l|c|c|}
\hline Yes & $4(16 \%)$ & $2(11 \%)$ \\
\hline No & $20(84 \%)$ & $16(89 \%)$ \\
\hline & & $P=0.685$ \\
\hline
\end{tabular}

\begin{tabular}{|c|c|c|}
\hline \multicolumn{3}{|c|}{ Tumour regression grade } \\
\hline $1-3$ & 15 (63\%) & $5(28 \%)$ \\
\hline $4-5$ & $9(37 \%)$ & $13(72 \%)$ \\
\hline & & $P=0.033$ \\
\hline
\end{tabular}

\section{Tumoural fibrosis}

\begin{tabular}{|l|c|c|}
\hline Mean & $22 \%$ & $30 \%$ \\
\hline$\geqslant 40 \%$ & $7(30 \%)^{\star}$ & $6(37.5 \%)$ \\
\hline$<40 \%$ & $16(70 \%)^{\star}$ & $10(62.5 \%)$ \\
\hline & & $* 1 \mathrm{pt} \mathrm{NE} ; * 2 \mathrm{pts} \mathrm{NE} ;$ \\
& & $P=0.74$ \\
\hline
\end{tabular}

\begin{tabular}{|c|c|c|}
\hline \\
\hline \multicolumn{3}{|c|}{$\begin{array}{l}\text { Tumoural necrosis } \\
\begin{array}{l|l}\text { Mean } & 42 \% \\
\end{array}\end{array}$} \\
\hline \multirow{2}{*}{$\begin{array}{l}\geqslant 50 \% \\
<50 \%\end{array}$} & \begin{tabular}{|c|c|} 
Mean & $42 \%$ \\
$\geqslant 50 \%$ & $12(52 \%)^{\star}$ \\
\end{tabular} & $2(12.5 \%)^{\star \star}$ \\
\hline & $11(48 \%)^{*}$ & $14(87.5 \%)^{\star \star}$ \\
\hline 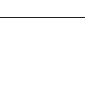 & & $\begin{array}{c}* 1 \text { pt NE; }{ }^{* * 2} \text { pts NE; } \\
P=0.017\end{array}$ \\
\hline
\end{tabular}

\section{Sinusoidal dilation}

\begin{tabular}{|l|c|c|}
\hline Grade 0 & $5(22 \%)^{\star}$ & $6(33 \%)$ \\
\hline Grade 1 & $10(43 \%)^{\star}$ & $7(39 \%)$ \\
\hline Grade 2 & $8(35 \%)^{\star}$ & $5(28 \%)$ \\
\hline & & *1 pt NE; $P=0.488$ \\
\hline
\end{tabular}

\section{Steatosis}

\begin{tabular}{|l|c|c|}
\hline Present (>5\%) & $7(30 \%)^{\star}$ & $7(39 \%)$ \\
\hline Absent & $16(70 \%)^{\star}$ & $11(61 \%)$ \\
\hline & & $* 1 \mathrm{pt} \mathrm{NE} ; P=0.74$ \\
\hline
\end{tabular}

\section{Steatohepatitis}

\begin{tabular}{l|c|c|}
\hline Present & $3(13 \%)^{\star}$ & $1(6 \%)$ \\
\hline Absent & $20(87 \%)^{\star}$ & $17(94 \%)$ \\
\hline & & ${ }^{*}$ pt NE; P=0.62 \\
\hline Parenchymal necrosis \\
\hline Present & $2(9 \%)^{\star}$ & $6(33 \%)$ \\
\hline Absent & $21(91 \%)^{\star}$ & $12(67 \%)$ \\
\hline \multicolumn{2}{|l}{} & *1 pt NE; P=0.1 \\
\hline Abbreviation: pt = patient; NE = not evaluable.
\end{tabular}

patients showing TRG 4 and $5(\mathrm{HR}=0.41,95 \% \mathrm{CI}=0.18-0.92$; $P=0.031)$. The same analysis restricted to the 'bevacizumab group' produced a significant difference $(\mathrm{HR}=0.25,95 \% \mathrm{CI}=0.05-0.73$; $P=0.015)$ that resulted in a similar, although not statistically significant, trend in the 'chemotherapy group' ( $\mathrm{HR}=0.57,95 \%$ $\mathrm{CI}=0.19-1.76 ; P=0.33$; Figure 3 ). According to the three-tier categorisation (TRG 1, 2 vs 3 vs 4, 5), in the 'bevacizumab group' a
Table 3. Comparison of response and toxicity parameters in treated and control patients

Treated $\mathbf{N}=\mathbf{4 2}$

Controls $\mathbf{N}=\mathbf{2 8}$

\section{Pathologic complete response}

\begin{tabular}{|l|c|c|}
\hline Yes & $6(14 \%)$ & $0(0 \%)$ \\
\hline No & $36(86 \%)$ & $28(100 \%)$ \\
\hline & & $P=0.040$ \\
\hline
\end{tabular}

\section{Tumour regression grade}

\begin{tabular}{|l|r|r|}
\hline $1-3$ & $20(48 \%)$ & $1(3.5 \%)$ \\
\hline $4-5$ & $22(52 \%)$ & $27(96.5 \%)$ \\
\hline & & $P<0.001$ \\
\hline
\end{tabular}

Tumoural fibrosis

\begin{tabular}{|l|c|c|}
\hline$\geqslant 40 \%$ & $13(33 \%)^{\star}$ & $1(3.5 \%)$ \\
\hline$<40 \%$ & $26(67 \%)^{\star}$ & $27(96.5 \%)$ \\
\hline & & $\star 3$ pts NE; $P=0.002$ \\
\hline
\end{tabular}

\section{Tumoural necrosis}

\begin{tabular}{|l|c|c|}
\hline$\geqslant 50 \%$ & $14(36 \%)^{\star}$ & $1(3.5 \%)$ \\
\hline$<50 \%$ & $25(64 \%)^{\star}$ & $27(96.5 \%)$ \\
\hline & & $\star 3$ pts NE; $P<0.001$ \\
\hline
\end{tabular}

\section{Sinusoidal dilation}

\begin{tabular}{|l|c|c|}
\hline Grade 0 & $11(27 \%)^{\star}$ & $11(52 \%)^{\star \star}$ \\
\hline Grade 1 & $17(41 \%)^{\star}$ & $10(48 \%)^{\star \star}$ \\
\hline Grade 2 & $13(32 \%)^{\star}$ & $0(0 \%)^{\star \star}$ \\
\hline & & ${ }^{\star 1} \mathrm{pt} \mathrm{NE} ;{ }^{\star \star} 7 \mathrm{pts} \mathrm{NE} ;$ \\
& & $P=0.045$ \\
\hline
\end{tabular}

\section{Steatosis}

\begin{tabular}{|l|c|c|}
\hline Present $(>5 \%)$ & $14(34 \%)^{\star}$ & $4(17 \%)^{\star \star}$ \\
\hline Absent & $27(66 \%)^{\star}$ & $20(83 \%)^{\star \star}$ \\
\hline & & ${ }^{\star 1} \mathrm{pt} \mathrm{NE} ;{ }^{*} 4 \mathrm{pts} \mathrm{NE} ;$ \\
& & $P=0.107$ \\
\hline
\end{tabular}

\section{Steatohepatitis}

\begin{tabular}{|l|c|c|}
\hline Present & $4(10 \%)^{\star}$ & $1(4 \%)^{\star \star}$ \\
\hline Absent & $37(90 \%)^{\star}$ & $22(96 \%)^{\star \star}$ \\
\hline & & $\star 1 \mathrm{pt} \mathrm{NE} ;{ }^{\star \star} 5 \mathrm{pts} \mathrm{NE} ;$ \\
& & $P=0.404$
\end{tabular}

\section{Parenchymal necrosis}

\begin{tabular}{|l|c|c|}
\hline Present & $8(20 \%)^{\star}$ & $0(0 \%)^{\star \star}$ \\
\hline Absent & $33(80 \%)^{\star}$ & $22(100 \%)^{\star \star}$ \\
\hline & & ${ }^{\star 1} \mathrm{pt} \mathrm{NE}^{* \star}{ }^{\star *} \mathrm{pts} \mathrm{NE} ;$ \\
& & $P=0.025$ \\
\hline
\end{tabular}

Abbreviation: $\mathrm{pt}=$ patient; $\mathrm{NE}=$ not evaluable.

trend towards a significantly different PFS outcome is reported $\left(\chi^{2}=5.19, P=0.07\right)$, whereas in the 'chemotherapy group' such an effect is not evident $\left(\chi^{2}=1.86, P=0.40\right)$.

In the population of treated patients, for each increment of 10 units in the percentage of necrosis there was a reduction of HR for PFS $(\mathrm{HR}=0.83,95 \% \mathrm{CI}=0.70-0.99 ; P=0.040)$. Overall, patients with liver lesions replaced by a necrosis rate $\geqslant 50 \%$ showed an advantage in PFS in comparison with patients with a necrosis rate 
A
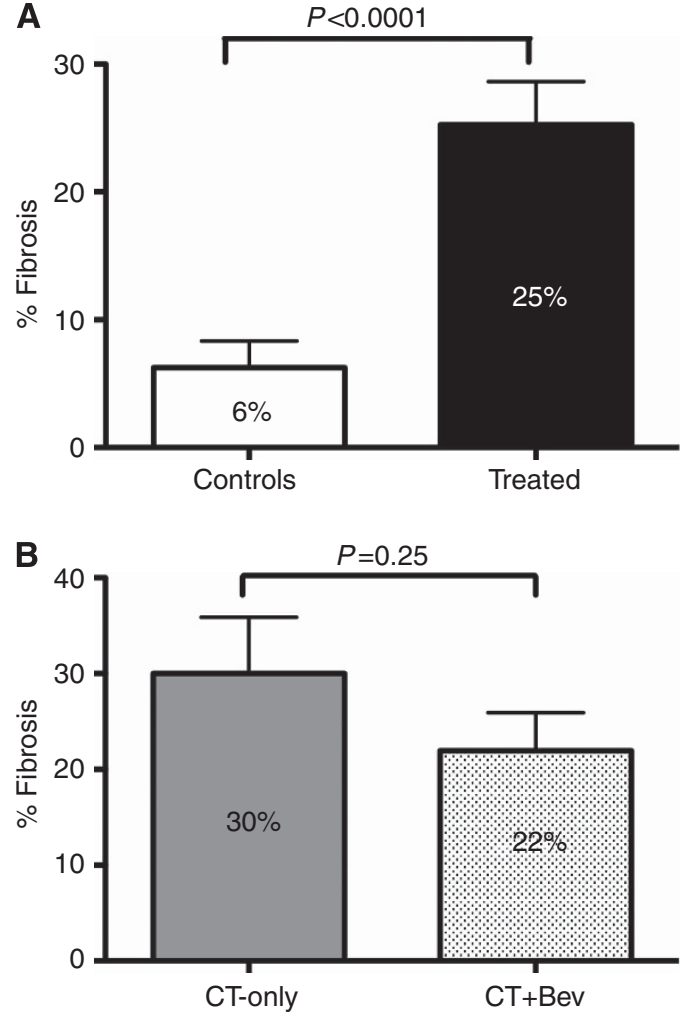

Figure 1. Fibrosis evaluation. (A) Mean fibrosis percentage in controls vs treated patients. (B) Mean fibrosis percentage in chemotherapy group (CT-Only) vs bevacizumab group (CT + bev).

$<50 \% \quad(\mathrm{HR}=0.38,95 \% \mathrm{CI}=0.19-0.97 ; \quad P=0.041)$. Subgroup analyses showed similar trends without reaching the level of statistical significance: 'bevacizumab group' ( $\mathrm{HR}=0.46,95 \%$ $\mathrm{CI}=0.14-1.51 ; P=0.20)$ and 'chemotherapy group' $(\mathrm{HR}=0.23$, 95\% CI $=0.09-1.24 ; P=0.10$; Figure 4 ).

Differences in the percentage of tumoural fibrosis did not affect the outcome.

The overall survival data were still immature at the time of the analysis.

\section{DISCUSSION}

An intensive chemotherapeutic approach with FOLFOXIRI combined to bevacizumab is a promising option for patients with unresectable mCRC. Encouraging results from a large phase II study were published 2 years ago (Masi et al, 2010) and new data will be available soon from a completed phase III randomised trial that tested the triplet plus the antiangiogenic as an experimental arm (http://clinicaltrials.gov/ct2/show/NCT00719797?term= tribe\&rank=5). The need for the highest activity coupled with major chances of disease control make such an intensive approach especially suitable for the conversion setting of potentially resectable CRC metastatic to the liver.

Here we report for the first time an analysis looking at the effects of FOLFOXIRI plus bevacizumab on CLM in terms of pathologic response and liver toxicity. Major findings of the present work were the following:

(1) an intensive approach (with or without bevacizumab) produced high pathologic response rates, mainly through the induction of fibrosis;

(2) the addition of bevacizumab to FOLFOXIRI improved pathologic response of CLMs;
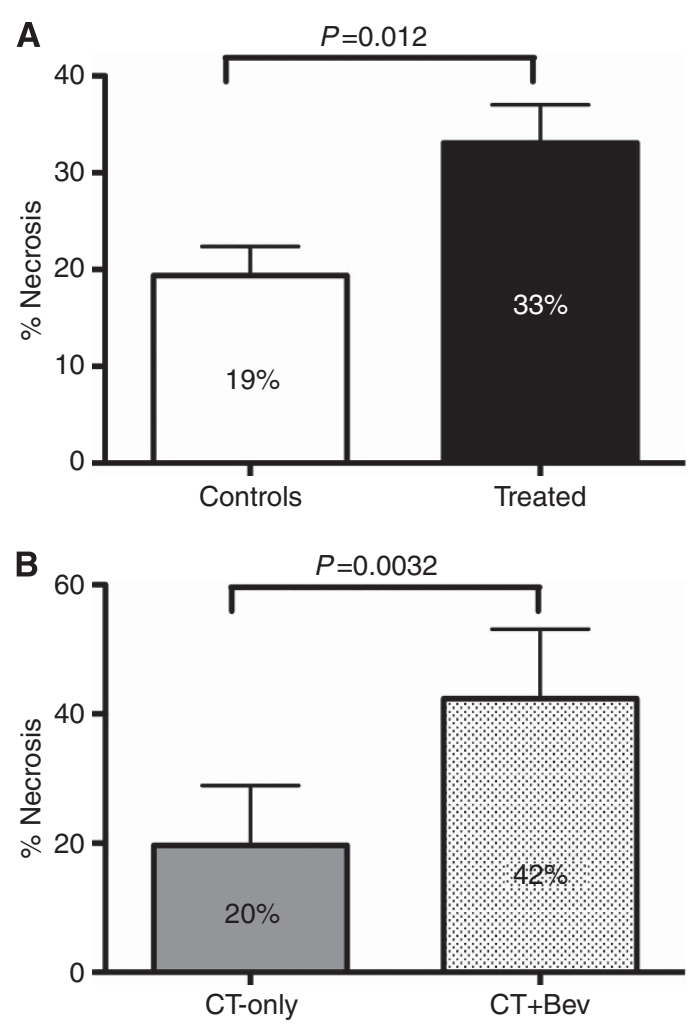

Figure 2. Necrosis evaluation. (A) Mean necrosis percentage in controls vs treated patients. (B) Mean necrosis percentage in the chemotherapy group (CT-Only) vs the bevacizumab group (CT + bev).

(3) the addition of bevacizumab to FOLFOXIRI increased the degree of necrosis in CLMs;

(4) confirmatory evidences regarding the correlation of pathologic responses and necrosis with the outcome;

(5) a four-drug regimen does not lead to an increase in liver toxicity.

We previously reported a high degree of pCR in CLMs treated with the FOLFOXIRI regimen (Masi et al, 2009). In the present study we observed a cumulative $14 \%$ pCR rate in patients treated with FOLFOXIRI plus or minus bevacizumab. These results compares favourably with data from the literature that usually range from $3 \%$ to $10-11 \%$ in most recent and large series of doublets with or without antiangiogenic (Ribero et al, 2007; Rubbia-Brandt et al, 2007; Kishi et al, 2010; Klinger et al, 2010). As already described (Rubbia-Brandt et al, 2007), pathologic response is achieved through the induction of fibrosis. This was also evident in our study $(25 \%$ vs $6 \%$ for treated $v s$ controls, $P<0.0001$; Figure $1 \mathrm{~A}$ ).

In our analysis, the addition of bevacizumab to the FOLFOXIRI regimen led to a general improvement in pathologic response of CLMs. This was not significant in terms of pCR $(11 \%$ for chemotherapy only vs $16 \%$ for the 'bevacizumab group'), but was more evident in terms of TRG. Actually, adding bevacizumab to FOLFOXIRI increases the chances of achieving a TRG of 1, 2 or 3 with an odds ratio of 1.833 . These data are consistent with previous findings obtained in series of patients treated preoperatively with oxaliplatin-based doublets plus or minus bevacizumab (Ribero et al, 2007; Klinger et al, 2010). In particular, Ribero et al (2007) studied 105 patients treated preoperatively with chemotherapy alone $(N=43)$ or with bevacizumab $(N=62)$ and reported a reduced percentage of residual viable tumour cells (45.3\% vs $32.9 \%$ for patients receiving the anti-VEGF; $P=0.02$ ). Klinger et al (2010) analysed 106 patients who received a preoperative treatment with fluoropyrimidines and oxaliplatin plus or minus bevacizumab and showed a $38 \%$ rate of TRG 1 or 2 in CLMs treated with the 
A Treated patients $(N=42)$
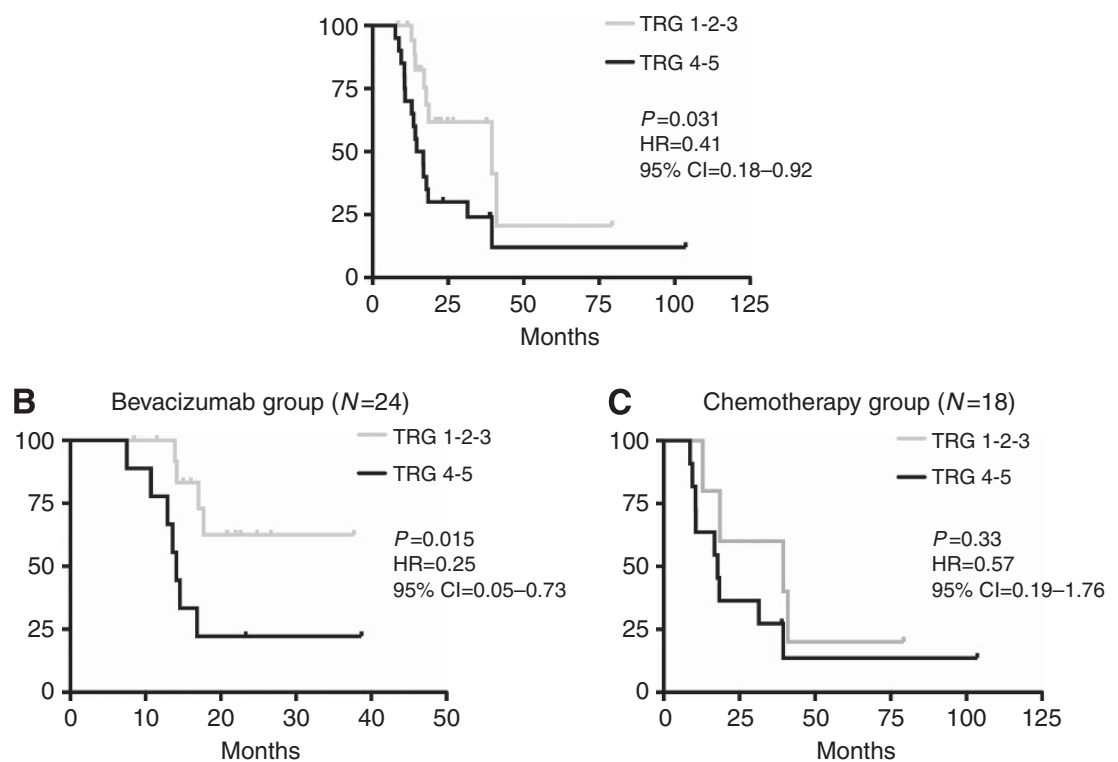

Figure 3. Progression-free survival (PFS) according to TRG. (A) Progression-free survival treated patients; (B) PFS in the bevacizumab group; (C) PFS in the chemotherapy group.

A Treated patients $(N=42)$
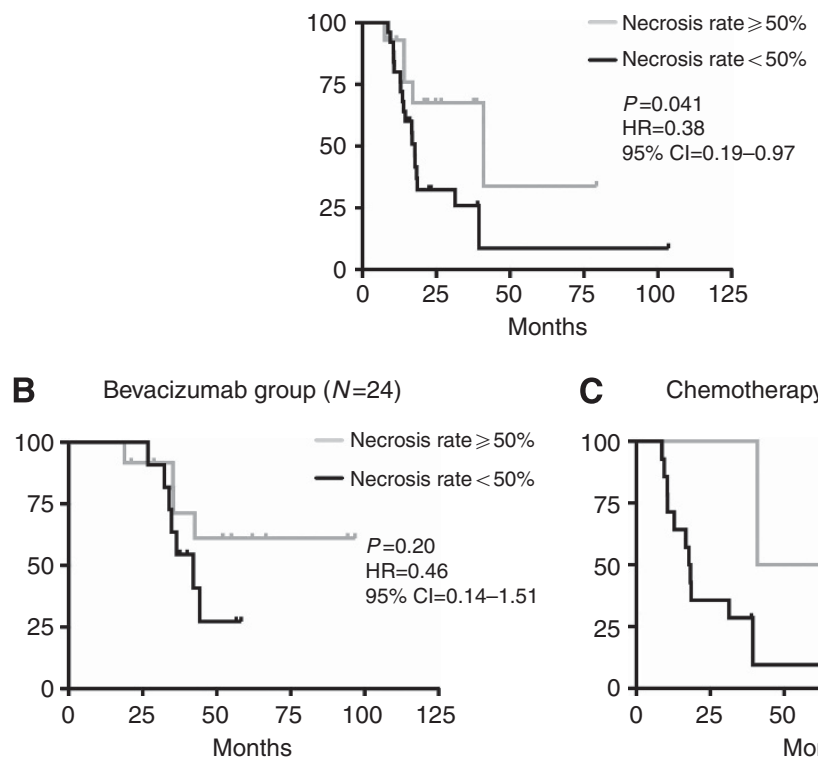

C Chemotherapy group $(N=18)$

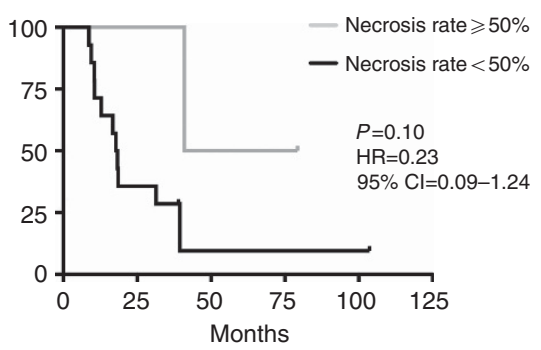

Figure 4. Progression-free survival (PFS) according to percentage of necrosis. (A) Progression-free survival treated patients; (B) PFS in the bevacizumab group; (C) PFS in the chemotherapy group.

antiangiogenic compared with $10 \%$ for those receiving chemotherapy only $(P=0.001)$.

Moreover, our data confirm the role of bevacizumab in inducing necrosis of CLM. These results are in line with preclinical and clinical data. It was shown how tumoural cells became necrotic as a consequence of an antivascular therapy due to tissue degeneration mediated by oxygen privation, whereas untreated tumours were protected from necrotic degeneration by a significant blood supply (Magnon et al, 2007). From a clinical perspective, in a recent study conducted on 164 patients who had resection of CLMs following preoperative chemotherapy with or without bevacizumab, the mean degree of tumour necrosis was significantly higher in the bevacizumab group (55\% vs 32\%; $P=0.001$ ) (Wicherts et al, 2011). Similar findings came from the study cited above from Klinger et al
(2010), in which treatment with bevacizumab was associated with a higher percentage of necrotic areas within the tumour.

Recently, Poultsides et al (2012) published a large retrospective analysis on 366 patients (68\% treated preoperatively and 32\% not) who underwent CLM resection. In that study there was no increase in the degree of necrosis. Nevertheless, it should be noted that only 69 out of 249 (28\%) patients had received bevacizumab as part of the preoperative treatment, and the results in terms of necrosis for that subgroup were not reported. In ours and other previous experiences (Klinger et al, 2010; Wicherts et al, 2011), the increase in necrosis seems to be a bevacizumab-related effect, as shown in Figure 1B.

Furthermore, we also found an association between clinical outcome and both pathologic response and necrosis rate. The 
relation between clinical outcome and TRG is a wellestablished point; in fact, some authors suggested that the degree of pathologic response might represent a new outcome end point for prognosis after resection of CLMs (Blazer et al, 2008; Gruenberger et al, 2012). The association of necrosis rate and clinical outcome is based on weaker suggestions at least in mCRC. In untreated colorectal cancer specimen, tumour necrosis has been proposed as an independent prognostic marker (Pollheimer et al, 2010), given its ability of influencing the host inflammatory responses.

Taken together, all the above-reported observations of reduced viable cells, fibrosis and necrosis explain from a pathological perspective the typical pattern of CLMs detected using CT scan in patients receiving chemotherapy and bevacizumab: before treatment the lesions show different modalities of enhancement, a heterogeneous degree of attenuation, and ill-defined borders that translate into hypoattenuating and homogeneous metastases with well-defined borders after treatment (Chun et al, 2009). Such histological and morphological characteristics strengthen the hypothesis that RECIST criteria are not adequate enough to evaluate response in patients receiving bevacizumab (Chun et al, 2009; Gruenberger et al, 2012).

In terms of hepatic toxicity, patients treated with the FOLFOXIRI regimen with or without bevacizumab showed an acceptable degree of liver injury, comparable to those reported in other series of patients treated with doublets of cytotoxic drugs (Rubbia-Brandt et al, 2004; Vauthey et al, 2006; Pawlik et al, 2007). We observed only a slight increase in parenchymal necrosis and in sinusoidal dilation for all treated patients compared with controls. The addition of bevacizumab to FOLFOXIRI did not increase any of the toxicity parameters analysed. We should admit that the present work cannot rule out small differences in the incidence of uncommon toxicities given its relatively low power. Small numbers may also explain the lack of evidence of a protective effect of bevacizumab against sinusoidal dilation, as previously reported (Ribero et al, 2007). It should be noted that patients treated with bevacizumab received a relatively inferior number of preoperative cycles and this may be partially explained as a bias caused by the different time frames in which the studies (with or without bevacizumab) were conducted. In recent years, the oncologist community progressively shifted to the adoption of a more limited number of conversion cycles for initially unresectable patients and this attitude influenced our centres as well. This was mainly because of the observation that extended preoperative treatment does not influence the activity, although it seems to increase the rate of postoperative complications (Wicherts et al, 2011). In the present study, response was assessed every 4 cycles and the median number of administered cycles in the bevacizumab group was 8 . Only $20 \%$ of patients further improved their response between cycle 4 and cycle 8 . On the other hand, these considerations strengthen the data on pathologic response in the present study, given that such results were achieved despite the lower median number of preoperative cycles administered in the 'bevacizumab group'.

The present work is limited by its retrospective and exploratory nature. Secondly, the role of bevacizumab was evaluated in two cohorts of nonrandomised patients. Moreover, because of the small sample size, we did not perform an interaction test that would have been useful to estimate the effect of bevacizumab on pathologic response and necrosis. Finally, a minor limitation is the lack of OS data because of the long postprogression survival of the patients. Despite these limitations, the present findings demonstrate a high 'histopathologic activity' and no major liver toxicities for the combination of FOLFOXIRI plus bevacizumab. Currently ongoing randomised trials will definitively assess clinical usefulness and importance of such combination.

\section{REFERENCES}

Adam R, Delvart V, Pascal G, Valeanu A, Castaing D, Azoulay D, Giacchetti S, Paule B, Kunstlinger F, Ghemard O, Levi F, Bismuth H (2004) Rescue surgery for unresectable colorectal liver metastases downstaged by chemotherapy: a model to predict long-term survival. Ann Surg 240: 644-657discussion 657-8.

Alberts SR, Horvath WL, Sternfeld WC, Goldberg RM, Mahoney MR, Dakhil SR, Levitt R, Rowland K, Nair S, Sargent DJ, Donohue JH (2005) Oxaliplatin, fluorouracil, and leucovorin for patients with unresectable liver-only metastases from colorectal cancer: a North Central Cancer Treatment Group phase II study. J Clin Oncol 23: 9243-9249.

Aloia T, Sebagh M, Plasse M, Karam V, Levi F, Giacchetti S, Azoulay D, Bismuth H, Castaing D, Adam R (2006) Liver histology and surgical outcomes after preoperative chemotherapy with fluorouracil plus oxaliplatin in colorectal cancer liver metastases. J Clin Oncol 24: 4983-4990.

Blazer 3rd DG, Kishi Y, Maru DM, Kopetz S, Chun YS, Overman MJ, Fogelman D, Eng C, Chang DZ, Wang H, Zorzi D, Ribero D, Ellis LM, Glover KY, Wolff RA, Curley SA, Abdalla EK, Vauthey JN (2008) Pathologic response to preoperative chemotherapy: a new outcome end point after resection of hepatic colorectal metastases. J Clin Oncol 26: 5344-5351.

Chun YS, Vauthey JN, Boonsirikamchai P, Maru DM, Kopetz S, Palavecino M, Curley SA, Abdalla EK, Kaur H, Charnsangavej C, Loyer EM (2009) Association of computed tomography morphologic criteria with pathologic response and survival in patients treated with bevacizumab for colorectal liver metastases. JAMA 302: 2338-2344.

de Gramont A, Figer A, Seymour M, Homerin M, Hmissi A, Cassidy J, Boni C, Cortes-Funes H, Cervantes A, Freyer G, Papamichael D, Le Bail N, Louvet C, Hendler D, de Braud F, Wilson C, Morvan F, Bonetti A (2000) Leucovorin and fluorouracil with or without oxaliplatin as first-line treatment in advanced colorectal cancer. J Clin Oncol 18: 2938-2947.

Douillard JY, Cunningham D, Roth AD, Navarro M, James RD, Karasek P, Jandik P, Iveson T, Carmichael J, Alakl M, Gruia G, Awad L, Rougier P (2000) Irinotecan combined with fluorouracil compared with fluorouracil alone as first-line treatment for metastatic colorectal cancer: a multicentre randomised trial. Lancet 355: 1041-1047.

Falcone A, Ricci S, Brunetti I, Pfanner E, Allegrini G, Barbara C, Crino L, Benedetti G, Evangelista W, Fanchini L, Cortesi E, Picone V, Vitello S, Chiara S, Granetto C, Porcile G, Fioretto L, Orlandini C, Andreuccetti M, Masi G (2007) Phase III trial of infusional fluorouracil, leucovorin, oxaliplatin, and irinotecan (FOLFOXIRI) compared with infusional fluorouracil, leucovorin, and irinotecan (FOLFIRI) as first-line treatment for metastatic colorectal cancer: the Gruppo Oncologico Nord Ovest. J Clin Oncol 25: 1670-1676.

Fernandez FG, Ritter J, Goodwin JW, Linehan DC, Hawkins WG, Strasberg SM (2005) Effect of steatohepatitis associated with irinotecan or oxaliplatin pretreatment on resectability of hepatic colorectal metastases. J Am Coll Surg 200: 845-853.

Folprecht G, Grothey A, Alberts S, Raab HR, Kohne CH (2005) Neoadjuvant treatment of unresectable colorectal liver metastases: correlation between tumour response and resection rates. Ann Oncol 16: 1311-1319.

Gruenberger B, Tamandl D, Schueller J, Scheithauer W, Zielinski C, Herbst F, Gruenberger T (2008) Bevacizumab, capecitabine, and oxaliplatin as neoadjuvant therapy for patients with potentially curable metastatic colorectal cancer. J Clin Oncol 26: 1830-1835.

Gruenberger T, Arnold D, Rubbia-Brandt L (2012) Pathologic response to bevacizumab-containing chemotherapy in patients with colorectal liver metastases and its correlation with survival. Surg Oncol 21: 309-315.

Hurwitz H, Fehrenbacher L, Novotny W, Cartwright T, Hainsworth J, Heim W, Berlin J, Baron A, Griffing S, Holmgren E, Ferrara N, Fyfe G, Rogers B, Ross R, Kabbinavar F (2004) Bevacizumab plus irinotecan, fluorouracil, and leucovorin for metastatic colorectal cancer. N Engl J Med 350: 2335-2342.

Kishi Y, Zorzi D, Contreras CM, Maru DM, Kopetz S, Ribero D, Motta M, Ravarino N, Risio M, Curley SA, Abdalla EK, Capussotti L, Vauthey JN (2010) Extended preoperative chemotherapy does not improve pathologic response and increases postoperative liver insufficiency after hepatic resection for colorectal liver metastases. Ann Surg Oncol 17: 2870-2876. 
Kleiner DE, Brunt EM, Van Natta M, Behling C, Contos MJ, Cummings OW, Ferrell LD, Liu YC, Torbenson MS, Unalp-Arida A, Yeh M, McCullough AJ, Sanyal AJ (2005) Design and validation of a histological scoring system for nonalcoholic fatty liver disease. Hepatology 41: 1313-1321.

Klinger M, Tamandl D, Eipeldauer S, Hacker S, Herberger B, Kaczirek K, Dorfmeister M, Gruenberger B, Gruenberger T (2010) Bevacizumab improves pathological response of colorectal cancer liver metastases treated with XELOX/FOLFOX. Ann Surg Oncol 17: 2059-2065.

Loupakis F, Bria E, Vaccaro V, Cuppone F, Milella M, Carlini P, Cremolini C, Salvatore L, Falcone A, Muti P, Sperduti I, Giannarelli D, Cognetti F (2010) Magnitude of benefit of the addition of bevacizumab to first-line chemotherapy for metastatic colorectal cancer: meta-analysis of randomized clinical trials. J Exp Clin Cancer Res 29: 58.

Magnon C, Galaup A, Rouffiac V, Opolon P, Connault E, Rose M, Perricaudet M, Roche A, Germain S, Griscelli F, Lassau N (2007) Dynamic assessment of antiangiogenic therapy by monitoring both tumoral vascularization and tissue degeneration. Gene Ther 14: 108-117.

Masi G, Allegrini G, Cupini S, Marcucci L, Cerri E, Brunetti I, Fontana E, Ricci S, Andreuccetti M, Falcone A (2004) First-line treatment of metastatic colorectal cancer with irinotecan, oxaliplatin and 5-fluorouracil/leucovorin (FOLFOXIRI): results of a phase II study with a simplified biweekly schedule. Ann Oncol 15: 1766-1772.

Masi G, Loupakis F, Pollina L, Vasile E, Cupini S, Ricci S, Brunetti IM, Ferraldeschi R, Naso G, Filipponi F, Pietrabissa A, Goletti O, Baldi G, Fornaro L, Andreuccetti M, Falcone A (2009) Long-term outcome of initially unresectable metastatic colorectal cancer patients treated with 5-fluorouracil/leucovorin, oxaliplatin, and irinotecan (FOLFOXIRI) followed by radical surgery of metastases. Ann Surg 249: 420-425.

Masi G, Loupakis F, Salvatore L, Fornaro L, Cremolini C, Cupini S, Ciarlo A, Del Monte F, Cortesi E, Amoroso D, Granetto C, Fontanini G, Sensi E, Lupi C, Andreuccetti M, Falcone A (2010) Bevacizumab with FOLFOXIRI (irinotecan, oxaliplatin, fluorouracil, and folinate) as first-line treatment for metastatic colorectal cancer: a phase 2 trial. Lancet Oncol 11: 845-852.

Pawlik TM, Olino K, Gleisner AL, Torbenson M, Schulick R, Choti MA (2007) Preoperative chemotherapy for colorectal liver metastases: impact on hepatic histology and postoperative outcome. J Gastrointest Surg 11: 860-868.

Pollheimer MJ, Kornprat P, Lindtner RA, Harbaum L, Schlemmer A, Rehak P, Langner C (2010) Tumor necrosis is a new promising prognostic factor in colorectal cancer. Hum Pathol 41: 1749-1757.

Poston G, Adam R, Vauthey JN (2006) Downstaging or downsizing: time for a new staging system in advanced colorectal cancer? J Clin Oncol 24: 2702-2706.

Poultsides GA, Bao F, Servais EL, Hernandez-Boussard T, Dematteo RP, Allen PJ, Fong Y, Kemeny NE, Saltz LB, Klimstra DS, Jarnagin WR, Shia J, D'Angelica MI (2012) Pathologic response to preoperative chemotherapy in colorectal liver metastases: fibrosis, not necrosis, predicts outcome. Ann Surg Oncol 19: 2797-2804.

Ribero D, Wang H, Donadon M, Zorzi D, Thomas MB, Eng C, Chang DZ, Curley SA, Abdalla EK, Ellis LM, Vauthey JN (2007) Bevacizumab improves pathologic response and protects against hepatic injury in patients treated with oxaliplatin-based chemotherapy for colorectal liver metastases. Cancer 110: 2761-2767.

Rubbia-Brandt L, Audard V, Sartoretti P, Roth AD, Brezault C, Le Charpentier M, Dousset B, Morel P, Soubrane O, Chaussade S, Mentha G, Terris B (2004) Severe hepatic sinusoidal obstruction associated with oxaliplatin-based chemotherapy in patients with metastatic colorectal cancer. Ann Oncol 15: 460-466.

Rubbia-Brandt L, Giostra E, Brezault C, Roth AD, Andres A, Audard V, Sartoretti P, Dousset B, Majno PE, Soubrane O, Chaussade S, Mentha G, Terris B (2007) Importance of histological tumor response assessment in predicting the outcome in patients with colorectal liver metastases treated with neo-adjuvant chemotherapy followed by liver surgery. Ann Oncol 18: 299-304.

Saltz LB, Cox JV, Blanke C, Rosen LS, Fehrenbacher L, Moore MJ, Maroun JA, Ackland SP, Locker PK, Pirotta N, Elfring GL, Miller LL (2000) Irinotecan plus fluorouracil and leucovorin for metastatic colorectal cancer. Irinotecan Study Group. N Engl J Med 343: 905-914.

Saltz LB, Clarke S, Díaz-Rubio E, Scheithauer W, Figer A, Wong R, Koski S, Lichinitser M, Yang TS, Rivera F, Couture F, Sirzén F, Cassidy J (2008) Bevacizumab in combination with oxaliplatin-based chemotherapy as first-line therapy in metastatic colorectal cancer: a randomized phase III study. J Clin Oncol 26: 2013-2019.

Vasile E, Masi G, Fornaro L, Cupini S, Loupakis F, Bursi S, Petrini I, Di Donato S, Brunetti IM, Ricci S, Antonuzzo A, Chiara S, Amoroso D, Andreuccetti M, Falcone A (2009) A multicenter phase II study of the combination of oxaliplatin, irinotecan and capecitabine in the first-line treatment of metastatic colorectal cancer. Br J Cancer 100: 1720-1724.

Vauthey JN, Pawlik TM, Ribero D, Wu TT, Zorzi D, Hoff PM, Xiong HQ, Eng C, Lauwers GY, Mino-Kenudson M, Risio M, Muratore A, Capussotti L, Curley SA, Abdalla EK (2006) Chemotherapy regimen predicts steatohepatitis and an increase in 90-day mortality after surgery for hepatic colorectal metastases. J Clin Oncol 24: 2065-2072.

Wagner JS, Adson MA, Van Heerden JA, Adson MH, Ilstrup DM (1984) The natural history of hepatic metastases from colorectal cancer. A comparison with resective treatment. Ann Surg 199: 502-508.

Wicherts DA, de Haas RJ, Sebagh M, Saenz Corrales E, Gorden DL, Levi F, Paule B, Azoulay D, Castaing D, Adam R (2011) Impact of bevacizumab on functional recovery and histology of the liver after resection of colorectal metastases. Br J Surg 98: 399-407.

Wood CB, Gillis CR, Blumgart LH (1976) A retrospective study of the natural history of patients with liver metastases from colorectal cancer. Clin Oncol 2: $285-288$.

This work is published under the standard license to publish agreement. After 12 months the work will become freely available and the license terms will switch to a Creative Commons AttributionNonCommercial-Share Alike 3.0 Unported License. 